TOWNSEND, K., (2016) Closely Held Secrets: Embodied knowledge in digitally crafted textiles, Chapter in Nimkulrat, N., Kane, F, \& Walton, K. Eds. (2016) Crafting Textiles in a Digital Age, Bloomsbury, 189-208 \& Plates 20-23.

\title{
Closely Held Secrets: Embodied Knowledge in Digitally Crafted Textiles
}

Katherine Townsend

\section{Introduction}

'Hold your beliefs lightly' (Perry 2010), 'They are taking it to the people' (Whalley 2010) and 'What a load of shit' (Fisher 2010) do not immediately conjure up the world of 'embroidery'. However, as titles of contemporary artworks, they do represent a significant moment in art and design where digital technology is accessible to allcomers and can be used and, some may say, misused accordingly.

This chapter explores the aesthetic and expressive potential of digital embroidery through reflection on a textile research project and exhibition, Closely Held Secrets (2008-2010). This two-year project was inspired by the working relationship between the artist Grayson Perry and technical embroidery designer Tony Taylor, and was further developed by Geoff Diego Litherland (exhibitions coordinator/artist) and the author, Katherine Townsend (principal investigator/textile practitioner). Supported and funded by the School of Art \& Design, Nottingham Trent University, the outcomes of the investigation culminated in an exhibition at the Bonington Gallery, opened by Janis Jeffries on 29 October 2010. The show featured artworks by Perry and eight other visual artists, most using digital embroidery as a creative media for the first time.

The key aim of Closely Held Secrets was to examine and reveal the often hidden, yet reciprocal relationship between technician and artist/designer; how the embodied knowledge of both parties is instrumental in the advancement of digital craft practice. The chapter includes insights into the private dialogue between the originator of an idea and the agent (and mode) of interpretation; how innovative outcomes are informed by vision but are ultimately achieved through human/machine interactions involving tacit knowledge, skills and trust.

Analysis of selected artworks from Closely Held Secrets illustrate how the multi-head embroidery machine can be used in a variety of ways: meticulously to 
replicate full-colour, hand embroidered techniques, expressively to convey abstract phenomena and intuitively to just 'see what happens'. The examples and accompanying narratives demonstrate how creative collaboration and intervention with digital technology can lead to novel outcomes that address diverse contexts, such as gender, ornamentation, mechanization, sexuality and space, through stitch.

The following sections discuss four aspects of the project beginning with the 'research context', an overview of 'digital embroidery' and the practice-led 'research methodology' that was applied. This is followed by an explanation of the two key approaches to digital embroidery, which emerged through the project as a 'method of replication' and an 'exploratory process'. The conclusion reflects on some of the outcomes of the project and the role of embodied knowledge in digital crafting practices. The artists' voices form a significant part of the chapter, through reflections on their individual motivations and the collaborative experience.

\section{Research Context}

The idea for Closely Held Secrets was inspired by the professional working relationship between Grayson Perry and Tony Taylor. Their creative partnership had developed since 1996 when a Nottingham embroidery company refused to digitize artwork of an ejaculating penis, incorporated into Perry's Tree of Death quilt design. They did however recommended another local company, Red Tape Designs, run by Taylor who accepted the commission with an open minded: 'don't worry you have reached the Channel 4 of embroidery'. ${ }^{1}$

The idea to highlight the creative exchange between an artist and a technical expert grew into a research project following initial conversations between Perry and Taylor, who approached Litherland and Townsend at the Bonington Gallery at Nottingham Trent University. In addition to working with Perry, Taylor was interested in working with a group of artists who were not necessarily embroidery specialists, but were keen to explore the potential of their different artistic practices through collaborative experimentation with digital embroidery. Following a call for participation via the Bonington Gallery in October 2008, a group of nine visual artists working in a variety of art and design practices such as fine art painting, sculpture, drawing and textiles were selected by Taylor. The group included Simon BeckMather, Craig Fisher, Charlotte Hodes, Geoff Diego Litherland, Danica Maier, Grayson Perry, Stella Whalley, Derek Sprawson and Katherine Townsend. 


\section{Digital Embroidery}

The digitization of textile design and production has enabled designers to devise hybrid approaches and generate digitally crafted outcomes integrating knowledge of traditional and advanced technologies. In practice digitization has fundamentally accelerated the textile process, resulting in fabrics that are no longer inscribed with the marks of temporality or 'a linear unfolding of history.'2 While some hand embroidered textiles can be difficult to distinguish from machine produced pieces, the capability and accessibility of digital embroidery technology has opened up the potential for a once painfully time consuming craft to be explored by creative practitioners who are rich in ideas but time poor. In the past an artisan would undertake hand embroidery to order, while a traditional craft practice is now often sourced offshore by luxury brands. In the commercial textile sector, handwork has generally been replaced by computer aided design and manufacturing (CAD/CAM) whereby intricate designs can be reproduced expediently. The technicians equipped to run this technology constitute a unique group of artisans, who possess the knowledge and skills of 'human centric, analogue and digital methods of creation.'3

Digital, or multi-head embroidery is a technically advanced version of machine embroidery, which was invented in the 1820 s to enable 'a female to embroider any designs with 80 or 140 needles as accurately and expeditiously as the former could do with one!'4 Taylor considers multi-head embroidery and the associated digitizing process to be 'essentially similar to traditional hand embroidery, made stitch by stitch; it's only the tools that are different'. ${ }^{5}$ For example, hand-stitched Petit Point designs necessitated a schematic, literally a 'plot', and digitizing requires a similar encoding process, whether as a physical working drawing (on squared paper) or as a virtual 'map' of the design on screen. As Taylor and Perry's creative relationship exemplifies, the automation of hand crafting processes using CAD/CAM has extended the possibilities for conceptual artists to diversify their practice using nontraditional media. As the specialist nature of digital embroidery technology can be difficult to access, it proved easy to assemble a group of artists interested in exploring it as an 'interdisciplinary/ intermedial' practice, with support from experts in this area. ${ }^{6}$

The title of the project and exhibition was suggested by Taylor through the following citation: 
It's a traditional art, it's creation, it's mechanical, it's electronic; it's difficult and at the same time easy. It's working with your hands, your head and your heart. Knowledge is gained by working with others who learned by doing and who are willing to divulge closely held secrets. ${ }^{7}$

Closely Held Secrets sought to reveal the nature of the often hidden dialogue between the originator of an idea and the agent of interpretation. The project challenged the myth that it is the technology that transposes an artist's ideas, rather than a skilled technician acting as a creative conduit between the artist and the technology. It explored how the exchange and realization of ideas requires each party to draw on embodied knowledge, to inform new methodologies and outcomes that extend the parameters of a particular media. The exhibition catalogue was designed to reflect how this collaborative process happens over time, but can be unacknowledged and forgotten (Figure 1a).

\section{Research Methodology}

The methodology adopted for the project was based on case studies of nine artists, undertaking a reflective, practice-led 'research through Art and Design'8 approach, over a nine-month period. The individual artists applied a variety of materials, developmental and action research methods to investigate digital embroidery, by customising the technology to make new artworks. ${ }^{9}$ Emphasis was placed on experimental collaboration, informed by the existing tacit skills of the technical experts and the developing knowledge of the artists, to provide new insights into the creative process of digital textile/ art production. ${ }^{10}$

The iterative, 'research as a learning process' 11 was documented by each group member using a variety of recording methods, including note and image making, photography, video and sound recording. Perry, who had used the medium before, had the clearest idea of an envisioned final outcome, but an exploratory 'what if?' 12 approach based on trust, intuition and at times leaps of faith, was embraced by most of the other members of the group. The physical translation of nine different artists' concepts proved intense during the realization stage between April and October 2010. It therefore became necessary to engage a second digital embroidery specialist, Tessa Acti, a recent postgraduate from Nottingham Trent 
University. Acti's MA Textile Design Innovation project explored 'the beauty of thread' by challenging the use of the multi-head technology to produce stitch structures to the optimum dimensions of the machine's working area. Her abstract design style together with her knowledge of programming and operating the machinery provided a symbiotic skill set to Taylor's artisanal approach of translating a master copy of an artwork onto point paper.

\section{Digital Embroidery as a Method of Replication}

This section discusses artworks created by Grayson Perry, Simon Beck-Mather and Charlotte Hodes, whose work was translated by Taylor into embroideries that placed strong emphasis on the original, graphic qualities of the artwork. It also considers works by Danica Maier and Craig Fisher, who worked with Taylor initially, but went on to collaborate with Acti in the digitization and stitching-out stages, resulting in intricate, decorative wall panels and a conceptual installation, respectively.

\section{Grayson Perry: Hold Your Belief's Lightly}
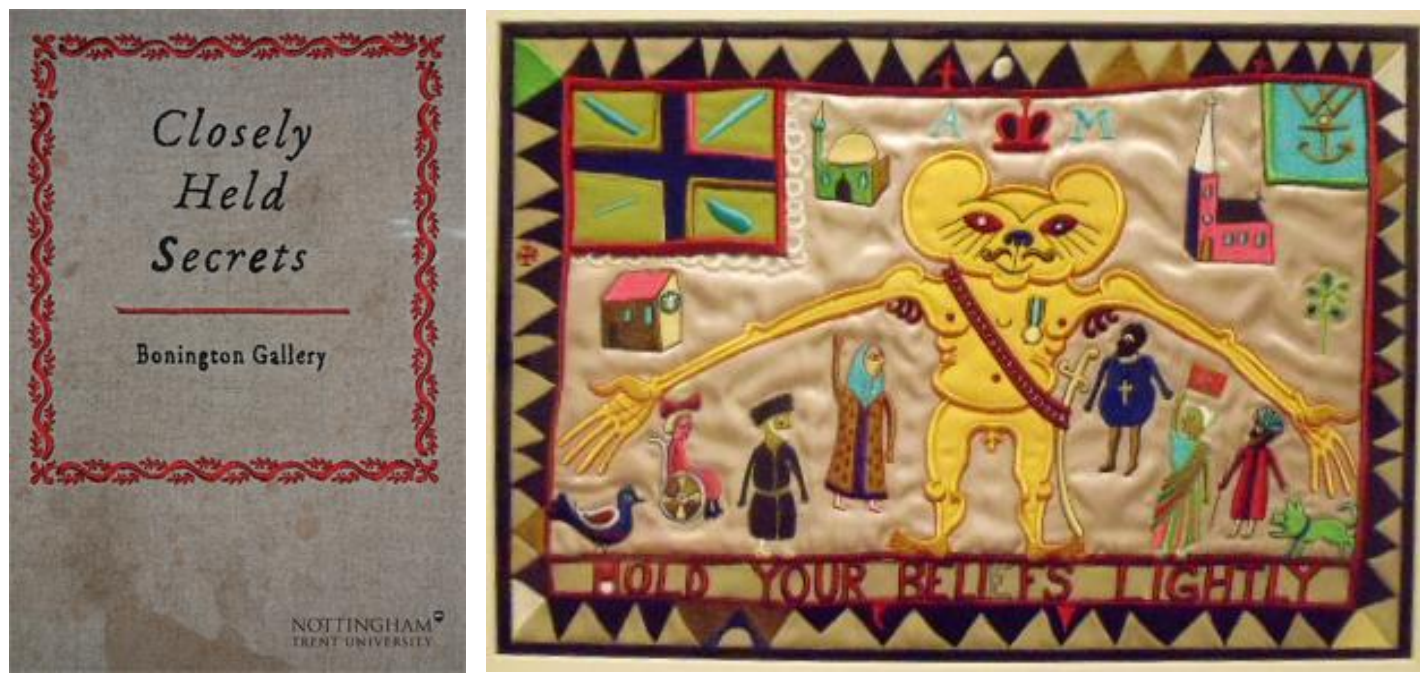

Figure 1a \& 1b: Closely Held Secrets exhibition catalogue designed by Litherland et al 2010. Photograph by K. Townsend (C) Bonington Gallery; 1b: Grayson Perry (2010): 'Hold your beliefs lightly'. Photograph S. Beck-Mather (C) G. Perry \& T. Taylor.

Perry designed a new artwork for Closely Held Secrets, inspired by African Asafo flags, prompting Taylor to question the artist whether the embroidery should be suitably 'rough and ready' in the general style of these textiles. Perry's response was to suggest the contrary that the stitching should be 'precise and luxurious like a 
pair of professional boxer's shorts'. ${ }^{13}$ The final design (Figure 1b) was translated by hand from a drawing. The design depicts Perry's famous teddy bear, Alan Measles, as a tribal leader in a surreal composition featuring leaders of the world's religions and Perry's alter ego, Claire (in a wheelchair) combined in the style of African ethnic insignia.

Through discussion, Perry and Taylor agreed that a combination of three satin appliqués, together with embroidered replication of the rich, colourful imagery, would produce the desired effect. The application of satin stiches on silk in carefully selected shades is visually seductive, while demonstrating the professional finish that can be achieved with all fifteen needles of the multi-head machine. The graphic, shiny finish met Perry's brief perfectly, but is paradoxical in terms of the subject matter depicted. The subversion of the use of stitch lies in the subject matter and detail inherent in the imagery rather than the meticulous process and quality of translation 'imprecise by design rather than in its execution'. ${ }^{14}$

Having worked together for so long, an understanding has evolved, whereby Taylor can grasp the artist's requirements regarding the 'feel' of each piece. In contrast with his ceramics, which though controversial visually often appear sketchy, spontaneous and naive, Perry uses embroidery in a more prescriptive, yet highly seductive manner. For example, the imagery on Claire's Coming Out Dress (2000), also featured in the exhibition, incorporates images from the artist's childhood including Alan Measles as an avenging primitive god. It also shows a struggling butterfly, symbolic of the transvestite coming out of the cocoon of puberty and a 'decriminalized penis with a bow around it, made to look cute like a pair of cherries on a child's dress'. 15

\section{Simon Beck-Mather: Children's Night Garden}

Beck-Mather's series of geometric embroideries were based on his painted wooden maquettes of the same name (Figure 2a). Embroidery was completely new territory for the artist, who was open-minded about how his work could be translated, allowing Taylor to take the lead. Though abstract in terms of their patterning, they fit within the 'replication' category because of the painterly exactitude with which Taylor carefully interpreted the intricate reliefs using various stitching methods and contrasting stitch directions to create a new entity (Figure $2 b$ ). 'Whilst the artist's original pieces are 3D 
by design, the thread patterns gave the embroideries a more subtle shifting physicality, dependant on both the position of the viewer and the light source.'1
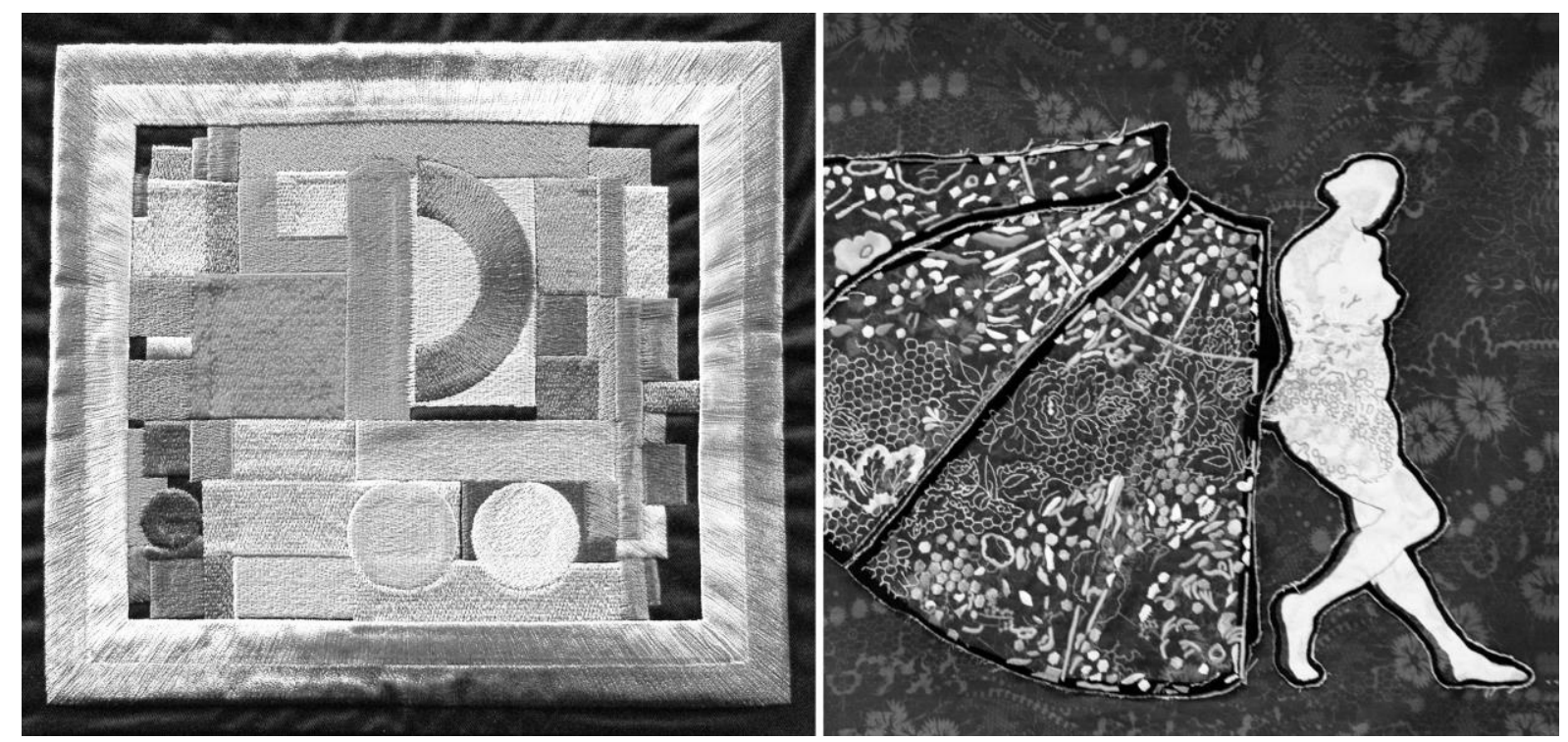

Figure 2a: Simon Beck-Mather (2010) An interpretation of Children's Night Garden as an embroidered artwork. Photograph by S. Beck-Mather (C) S. Beck-Mather; Figure 2b: Charlotte Hodes (2010) Section of embroidered applique based on the series of Wave drawings and paper cuts. Photograph by D. Whitmore (C) Charlotte Hodes.

For Taylor, working with Beck-Mather was the ultimate exchange between artist and artisan in Closely Held Secrets, inasmuch as he had to 'prise' out the artist's original intentions regarding his existing pieces, and then engineer the new artworks by means of the 'secrets' of embroidery digitizing. ${ }^{17}$ This relationship is in stark contrast to the one Taylor experienced with Perry, who originated his artwork with the embroidered outcome clearly in mind, whereas Beck-Mather was working in unknown aesthetic territory.

\section{Charlotte Hodes: Wave}

Hodes provided Taylor with finished artwork for Wave (2009/10) a collection of largescale (A0) printed/paper cuts inspired by classical Greek figures, which he synthesized to create a single, intricate piece. Hodes was fascinated by the possibilities of translating her work, recognizing that the tactile, collaged surfaces of imagery and pattern of her paper cuts shared many of the qualities that are inherent in embroidery. The major challenge was how to use the paper cuts (Figure 3a) as a 
starting point for digital embroidery through combining inkjet printing with multi-head embroidery to articulate the layered qualities of the drawings.

We were acutely aware of the embroidery threads being my drawing tool, equivalent to the cut lines of the scalpel blade in the paper. These threads weave a complex, intricate layer across the surface, holding together the digitally printed areas, patterns and shapes. ${ }^{18}$

The resulting piece (Figure $2 b$ ) featured richly coloured floral elements juxtaposed with a figure and fan-shaped skirt translated as monochromatic, lacepatterned appliqués, superimposed upon a digital print. Taylor considered this synthesis of textile approaches to illustrate a 'tacit conspiracy' between artist and artisan:

The 'physicality' of embroidery is important here; the relatively muscular quality of the stitches and appliqué set against the fine precision of Charlotte's original paper cuts was particularly effective. ${ }^{19}$

\section{Craig Fisher: What a Load of Shit}

In the exhibition catalogue for Closely Held Secrets, Fisher tells an amusing tale of how he once spent an entire two-week package holiday sewing sequins onto an artwork. The attention and amusement it created among his fellow holiday makers when they discovered it was not a map of Majorca, but 'a big pile of vomit!'20 Fisher's account underpins his ongoing exploration of the subversive potential of 'the ornamental' through his process of making. In Closely Held Secrets, his aim was to work with Taylor and digital technology to make 'the most beautiful pile of crap' that he could. ${ }^{21}$

In the event, Taylor digitized Fisher's numerous, varying sized motifs designed to resemble cartoon-style bird droppings and Acti stitched them out to the artist's specific requirements. As Acti observed, Fisher 'explored layering, placement, tonal colour and replication, slightly changing each piece so it challenged the perception of repetition'. ${ }^{22}$ The embroidered 'shits' formed part of a site specific installation, where they were placed to appear randomly splattered on an arrangement of fuchsia and grey planks of wood, concrete manholes and hazard 
tape, crafted in plush, padded textiles. ${ }^{23}$ As illustrated in Figures $3 a$ \& b, the floor based artwork occupied approximately $2 \times 3$ square metres of space, inviting the viewer to enter a scene of seductive detritus, where undesirable objects are playfully executed and adorned using the latest technology, presenting an ironic pairing of 'hazardous materials' and craft. ${ }^{24}$
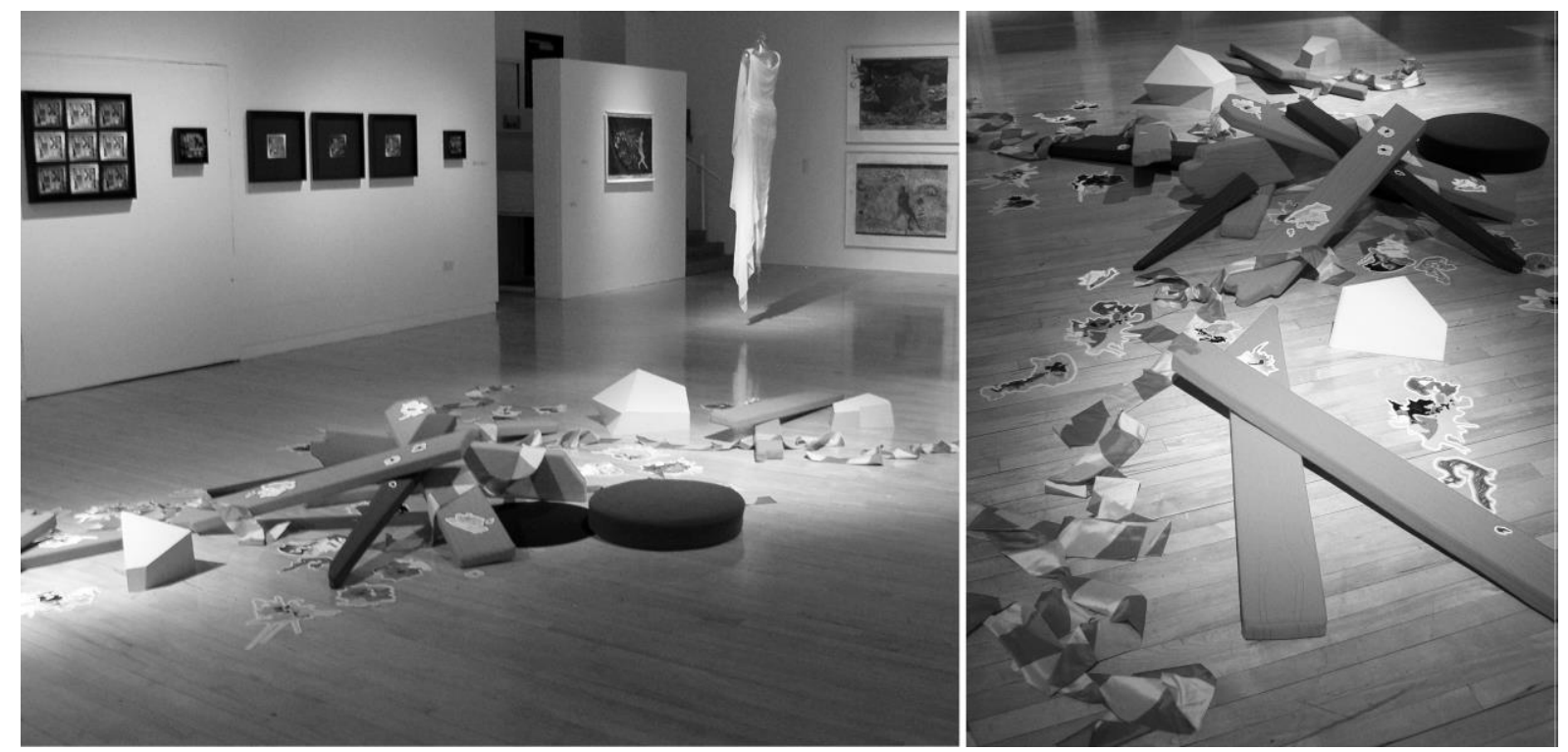

Figure 3a \& 3b: Craig Fisher (2010) Views of the installation, 'What a load of shit', Bonington Gallery, Nottingham Trent University. Photographs by S. Beck Mather (O) C. Fisher

Fisher's paradoxical approach to textile embellishment was reinforced by Kane's review of the exhibition:

Fisher's work underpinned the theme of ornamentation running through the show, but explicitly addressed the subversive potential of the decorative in relation to notions of masculinity ... touching upon ideas of mechanization and industry ... From an aesthetic perspective, Fishers digitized piece was ambitious in its approach to surface ... and perhaps glamorous. ${ }^{25}$

\section{Danica Maier: Harlequin Slit}

For Maier, 'the act of drawing repetitive lines one after another, camouflaging letters and words within pretty patterns is in itself like the act of embroidery' and it is this repeated act of stitching, making and drawing that she enjoys doing. ${ }^{26}$ The works themselves have multiple levels of reading and understanding. Firstly, the decorative 
image is seen, then the different stitching techniques or 'marks', finally and only to those willing to look, does the text reveal itself and unravel the original understanding of the work.

For Closely Held Secrets, Maier used a combination smooth, padded and overstitching techniques to create a series of wall mounted, parallelogram-shaped panels, featuring silver grey thread on dark grey (Figure 5b) and scarlet silk. Maier enjoyed the physicality and practice of generating the digital element and worked very closely with Acti, learning how to program using the Wilcom software.

The repeated action of using a digital line to create the instructions for the machine to work from seemed to mimic the repeated action of drawing. While the repeated act of the embroidery machine hiding the lovely silk underneath seemed to inverse the expectation that in drawing the line is used to reveal. Stitched line, drawn line-both the same-a line used to direct the attention of the eye. ${ }^{27}$

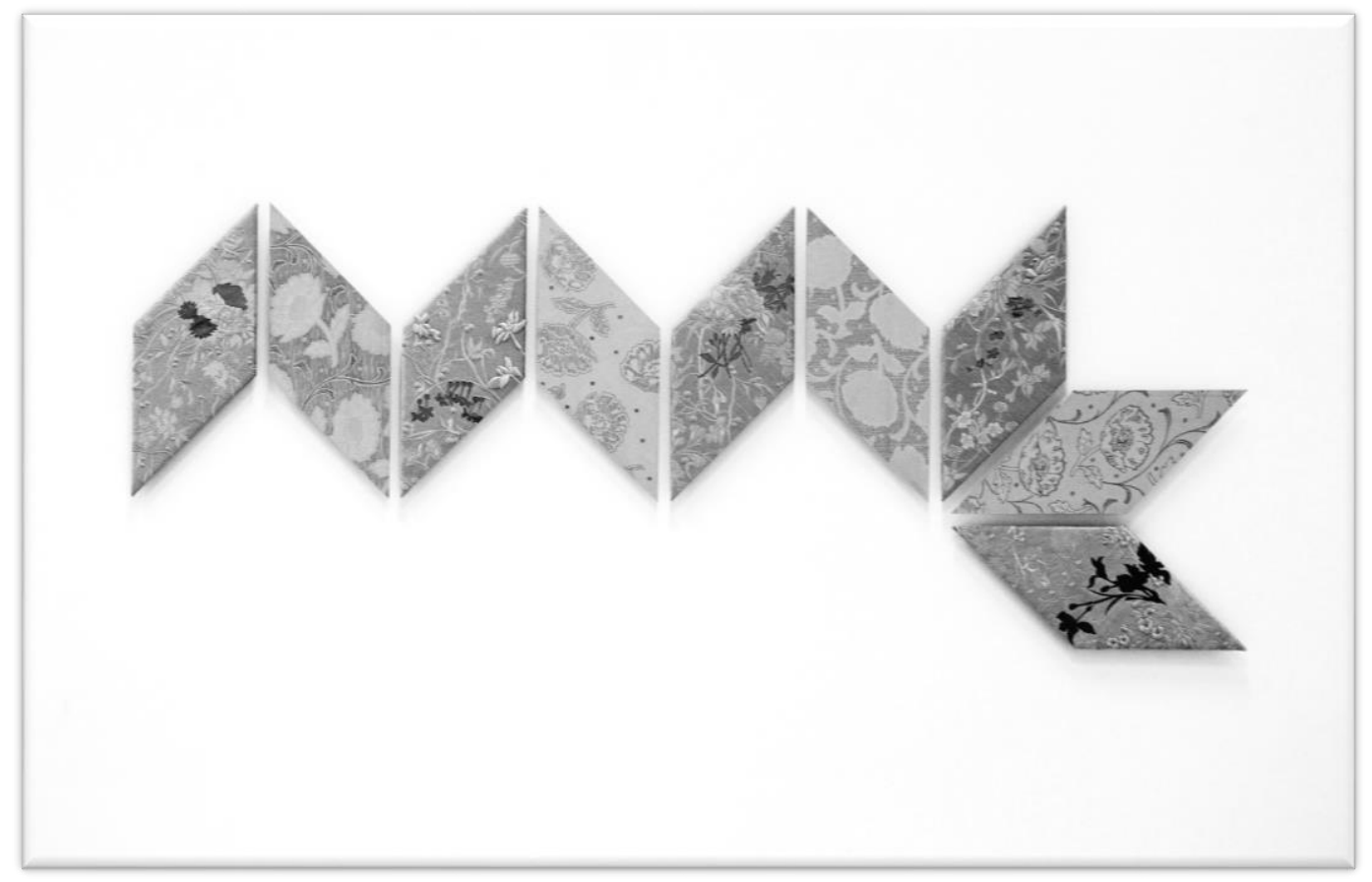

Figure 4: Danica Maier (2010) Harlequin Slit. Photograph D. Maier @ D. Maier

Maier was shown how to digitize and asked for advice regarding technical (how to) detail alongside aesthetics. Her hand embroidery background helped her to 
visualize the pieces created with more ease, than some of the other artists who had no embroidery knowledge. Acti reflected:

The people who worked more closely with me felt as though they had more control, investment and connection with the process and created a truer reflection of what they wanted to convey through the pieces. Also, Maier, Litherland, Townsend and to some degree Fisher, had more appreciation of the time, limitations and challenges, which comes from the real-time engagement with the machine, i.e. being present during the stitching out process. $^{28}$
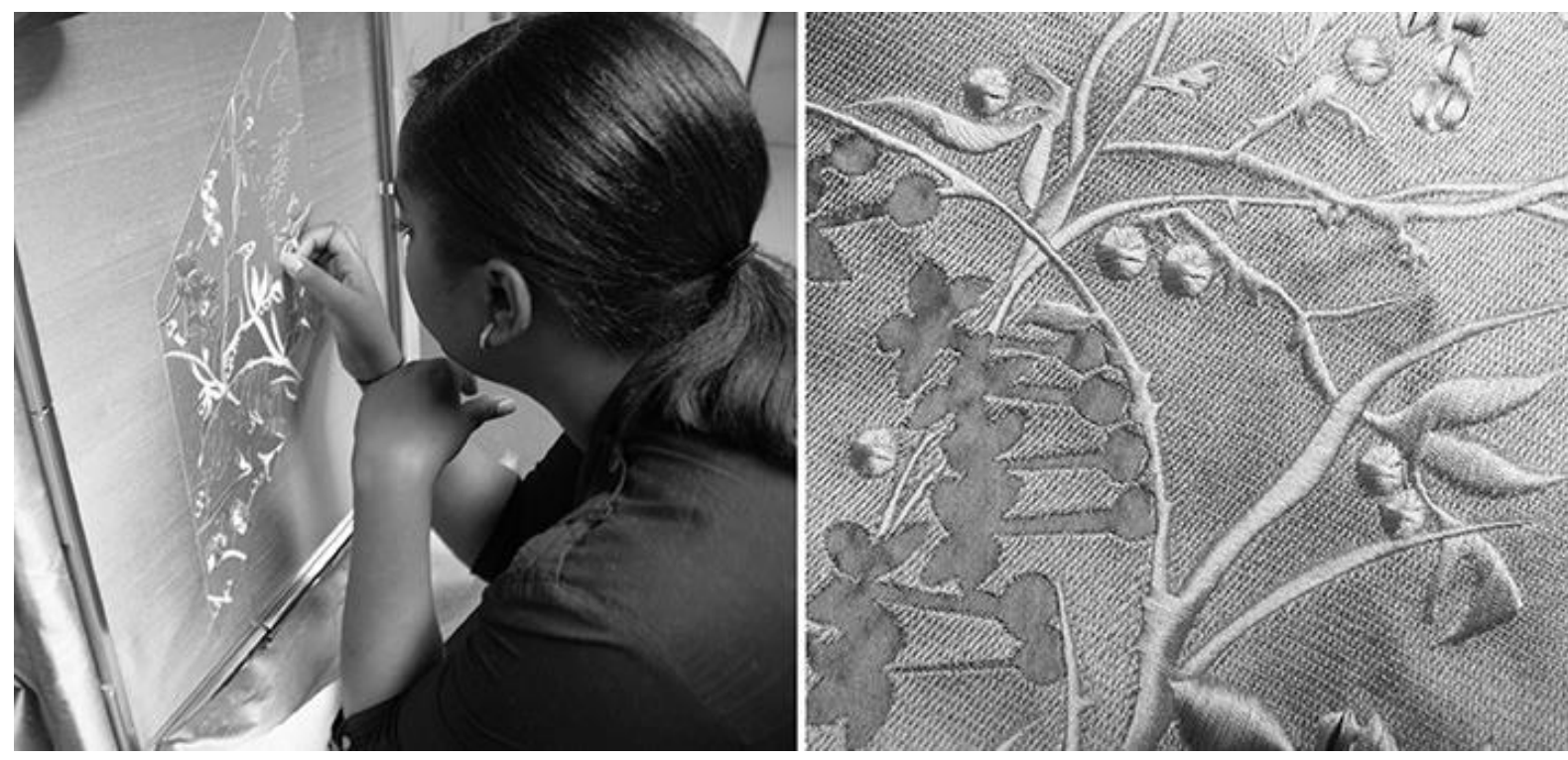

Figure 5a: Tessa Acti working on Danica Maier's Harlequin Slit. Photograph by Debbie Whitmore (c) Bonington Gallery; Figure 5b: Detail from one of Maier's panels illustrating how the artist accentuated the negative space of the background silk by applying smooth and raised stitch effects. Photograph by D. Whitmore () D. Maier

\section{Digital Embroidery as an Exploratory Process}

This section discusses Derek Sprawson's, Stella Whalley's and Geoff Diego Litherland's artworks that were digitized by Taylor and stitched out by Acti, and Katherine Townsend's work whose ideas were translated in collaboration with Acti. The members of this group had fewer preconceptions about the qualities and overall appearance of the final artworks, allowing the process to influence the outcome. 
For some time Sprawson had imagined how the imagery he painted would translate into embroidery. Finding himself undergoing a shake-up of his 'comfortable mode of making', he was excited by the opportunity to collaborate with Taylor to produce something he hoped would satisfy his curiosity. Sprawson's starting point was globules of oil paint mixed with a solution of beeswax spattered onto stained canvas by pressing sheets of acetate onto the surface. The organic forms of the waxy, oily smears enthralled him. Having digitally scanned these shapes he presented Taylor with a USB and asked him to explore how these scans might emerge as embroidered images. Following a week of artistic interpretation by Taylor, Sprawson's digitized artwork was uploaded to the multi-head machine by Acti and stitched out:

\begin{abstract}
Watching the thread, the needles dance over the surface of the cloth choreographed by the drawings Tony had extracted from my smears was probably the highlight of this whole experience for me. The precision and dexterity with which the form emerged was riveting. I could see the form of the smeared shape I had given to Tony but the colours of the thread, the scale of the shape and the tactility of the surface now read as something completely different. ${ }^{29}$
\end{abstract}

The translation of the smears presented Taylor with a particular challenge. Due to their amorphous nature, he processed the original scans by repeatedly rendering them in Paint Shop Pro 'enhancing the sharpness, and contrast, until they began to take the form of natural topographical features complete with contours as on an ordnance survey map, just as Derek hoped they might'. ${ }^{30}$ Sprawson's and Taylor's conceptual collaboration raises parallels with the notion, explored by Sol LeWitt that 'an idea embodies its own logic of production and that its narrative potential could automatically unfold to achieve its full or total expression' ${ }^{31}$

\title{
Stella Whalley: They are Taking It to the People
}

Stella Whalley's stylized graphics based on a research visit to Tokyo ${ }^{32}$ provided Taylor with a completely different set of artistic parameters to work within. Whalley felt that Taylor had the skill to translate her different drawing styles into embroideries, and discussed her contrasting mark making approaches with him suggesting the 
tone and textures of the threads and stitch techniques. For example, she wanted a stitch to reflect the scratchy pen drawing of the Wolf piece, with lots of long stitches and rough loose threads (Figure 6a). She gave Taylor a challenge by using graduated tonal colour, as on the 'play girl's' body and 'girl with fish' where he applied a stitch that changed direction to effectively pick up various tones (Figure 6a). Whalley was impressed by the amount of stitches Taylor had to plot to animate the qualities and characters in the drawings using running stiches as outlines and infilling with satin stitch to create rich embossed, 3D surfaces that caught the light. Like Sprawson, she was also mesmerized by the automated stitching process:

I love watching the multi-head machine in its process, its robotic jabbing movement over the fabric; machines now can automatically snip threads, thread needles and change colours, but there is still the hands-on skill of its operator in programming and setting up, making sure the fabric and needle work together without tearing the surface. I like the multiplicity of this process, as in print these stages can be separated. ${ }^{33}$

Whalley's account references what Harris (2012) refers to as 'digital practice in material hands ${ }^{\prime 34}$ how it is still dependent on the dexterity of nimble finger work and timely intervention to progress the technology strategically or prevent machine error. She was seduced by the relationship between man and machine, the programming and reprogramming activities of a 'human computer' ${ }^{35}$ Her enthusiasm for the medium followed initial reservations about its limitations, how it could enhance her work, and whether her ideas were practically possible to realize. However, it was clear to Taylor that the physicality of embroidery would be a perfect foil for her artwork; that the print and embroidery would 'jump off' the surface in turns. The translation process necessitated 'a leap into the unknown' since the scale of the pieces required multiple (and manual) manipulation of the fabric within the stitching frame for the embroidery to be accurately registered upon the printed substrate. ${ }^{36}$ 


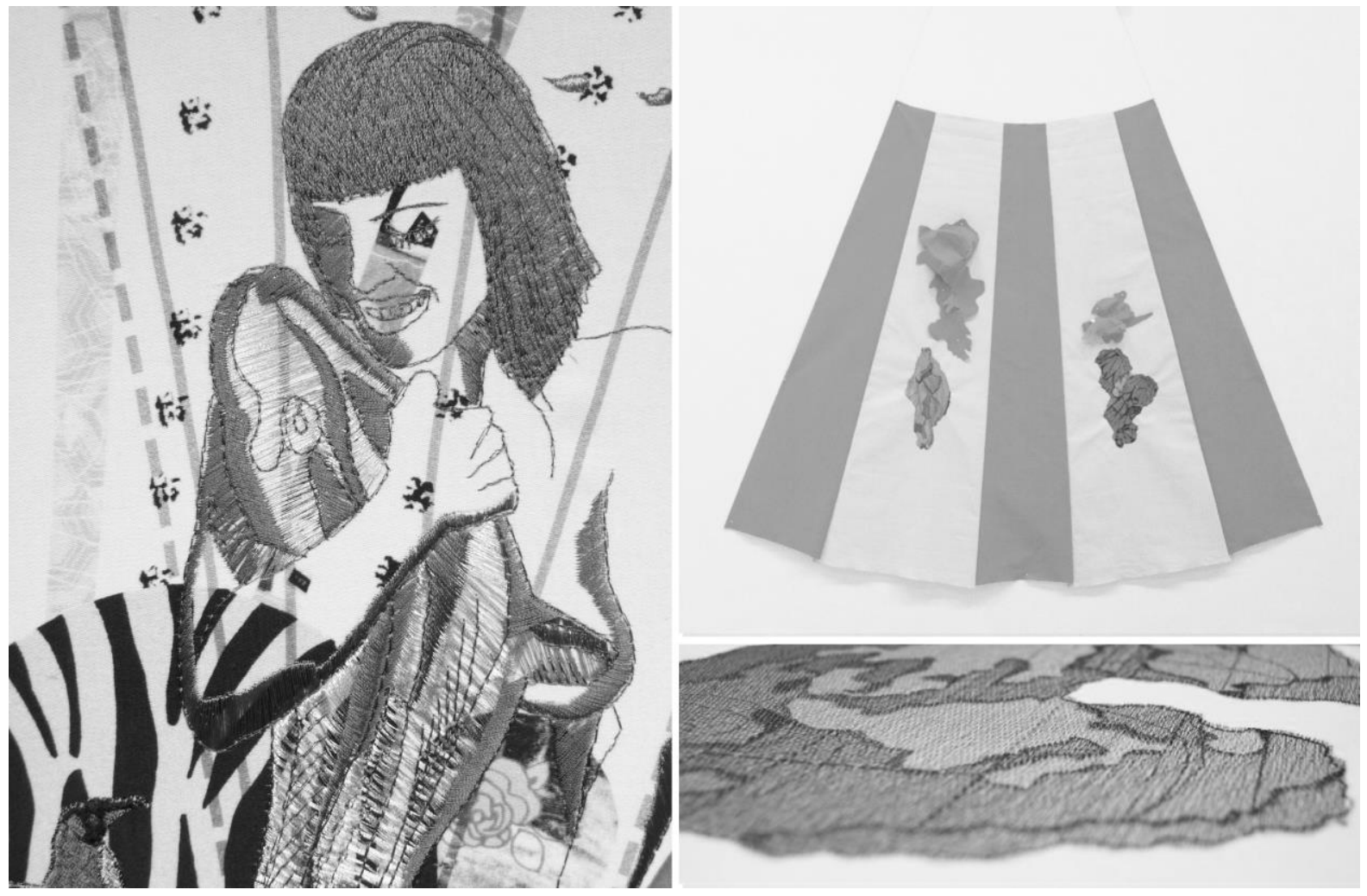

Figure 6a: Stella Whalley (2010) 'girl with fish' from They are Taking it to the People showing satinstyle stitches superimposed over digitally printed imagery. Photograph by S. Beck-Mather () S.Whalley; Figure 6b \& 6c: Derek Sprawson (2010) Part of Evidence of 20,000 Saints and detail of motif based on oil smear. Photographs by D. Whitmore (C) D. Sprawson.

While Taylor completed the digitizing aspect the level of manual intervention required to superimpose stitches accurately over digital prints could not be outsourced. ${ }^{37}$ Like most of the pieces, it was stitched out by Acti, who acknowledged that this was 'the most difficult piece to navigate, as the fabric was larger than the surface area of the multi-head frame. ${ }^{38}$ Despite Acti's rigorous approach, the disparity between the scale of printed and digitized visual elements resulted in some accidental, surreal effects, which contributed to the expressive style of the final textiles (Figure 6c).

\section{Geoff Diego Litherland: All the Stars and Invaders}

Litherland experimented with integrating the digital embroidery into his painting practice. Like his paintings, which strongly reflect the actions and materiality of their making, it was important to him that the final outcomes for Closely Held Secrets were influenced by the various processes involved: from the initial conversations to the design of the motif and the embroidery itself. From the start he aimed to subvert the 
idea of the embroidered motif, 'the default use of the technology and imagined what would happen if a malignant consciousness entered the machinery and took control of the production'. 39

For All the Stars, I wanted to set up parameters that enabled an approach not dissimilar to the way that some minimalist composers create music, one layer at a time. And like Terry Riley's In C piece, I wanted to allow the performer, in this case Acti was controlling the multi-head machine, a space to be intuitive and improvise. The stars were digitized by Tony and I picked 24 colours and roughly laid out 5 layers of 10 stars each, but Acti picked the final colour combinations and layouts. I wanted the previous layer and background painting to direct but not dictate the overall composition. 40
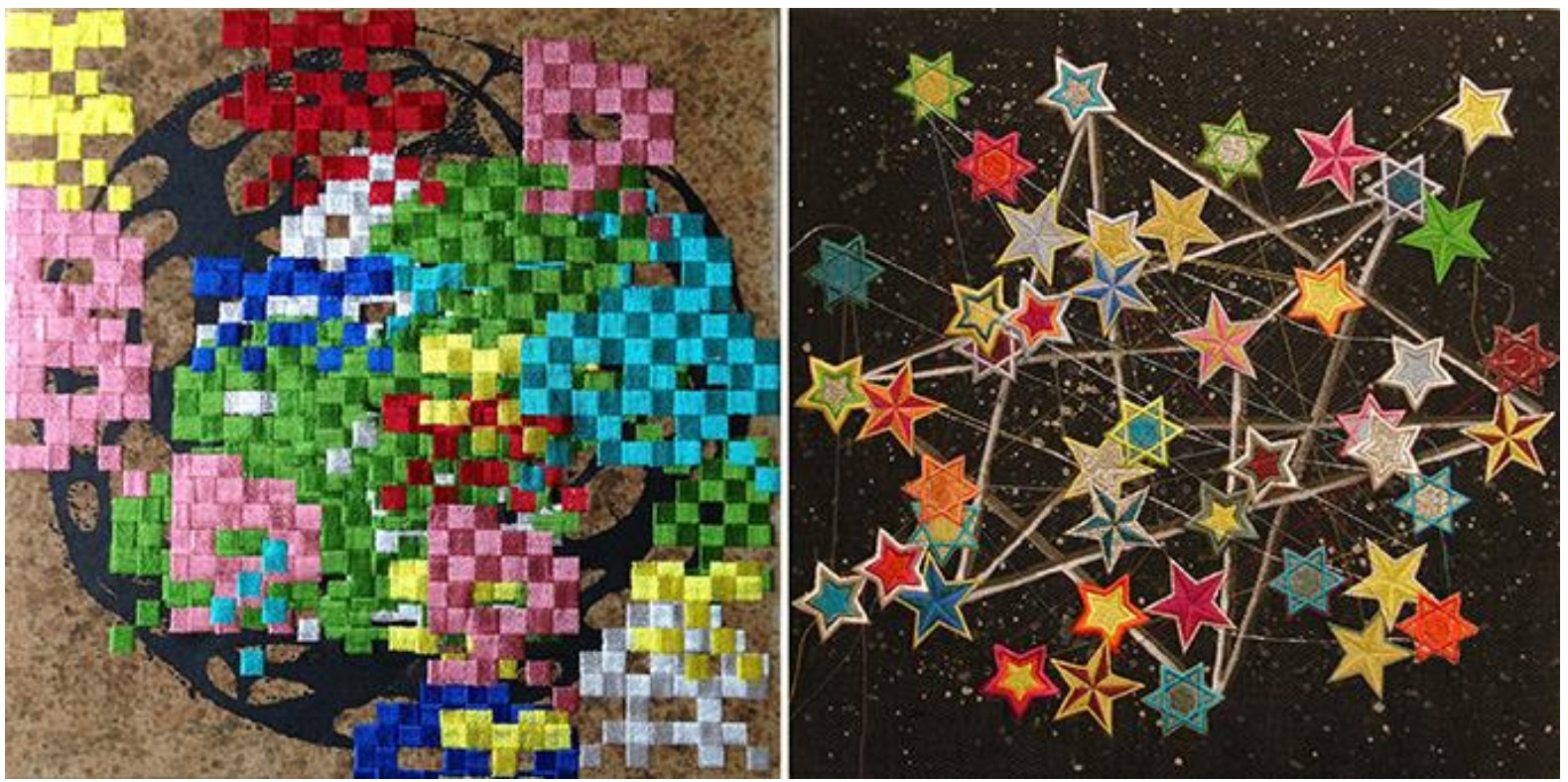

Figure 7a \& 7b: Geoff Diego Litherland (2010) Invaders (left) comprised of multiple layers of embroidered threads to suggest different coloured pixels. Photograph K. Townsend (C) G. Diego Litherland; All the Stars. Photograph by S. Beck-Mather ( ) G. Diego Litherland.

The initial imagery for Invaders was inspired by the 1980s arcade game Space Invaders; with its block-style pixels it had an obvious connection with digitization. Litherland was interested in exploring the sci-fi connotations 'ghost in the machine'. The first layer was based on a formal composition worked out in Photoshop. However, when stitched out, subsequent layers of the same composition 
were started from a different point and so on, resulting in a thick layer of stitching, which mimicked the artist's impasto painting style and challenged the machine's technical capability. Litherland and Acti decided from the outset that there would be no specific aesthetic conclusion to the process but they would stop when there was a risk of breaking the embroidery equipment. ${ }^{41}$ In order to promote this element of chaos, Litherland gave Acti some rules and parameters as to how to produce the pieces, with the aim of creating a generative image that was constructed not only by the limits of the technology, but also by intuition, communication or miscommunication and error. ${ }^{42}$

\section{Katherine Townsend: Lace Flow 1-3}

The three textile lengths developed by Townsend for Closely Held Secrets were inspired by the patterning synergies between water and lace: the juxtaposition of an elemental fast flowing rhythm with static, organically inspired fabrications. ${ }^{43}$ The pieces explored the potential for combining multi-head embroidery with inkjet printing: how both processes can be used to photographically replicate visual and textural detail, but more significantly how these technologies can be applied nonprescriptively to abstract and innovate rather than duplicate. ${ }^{44}$

The Baradun multi-head machine used in this project has fifteen needles on each head and a working surface of $45 \times 52 \mathrm{~cm}$. Townsend became fixated on what would happen if she stripped the machine back to a single thread in a single colour and how she could utilize the working canvas to stitch images that permeated lengths, rather than create small detailed samplers. The use of one needle and thread referenced traditional hand embroidery, which early machines were devised to replicate.

In practice, this presented problems - the machine did not respond well to this limitation, and stopped regularly, due to the uneven tension created on the cloth's surface by the needle's piercing/threading action. This required Townsend or Acti to regularly have to restart and rethread the machine needle, generating a complimentary set of manual movements and a disjointed woman-machine rhythm.

Other hands-on interventions included moving the digitally printed silk base to assimilate stitch and image sympathetically, or to create large-scale elements by joining mirrored motifs (such as the 'horseshoe collar' and large 'pylon') stitched in two halves to create embroidered motifs, some measuring $80 \times 100 \mathrm{~cm}$ (Figure. 8b). 

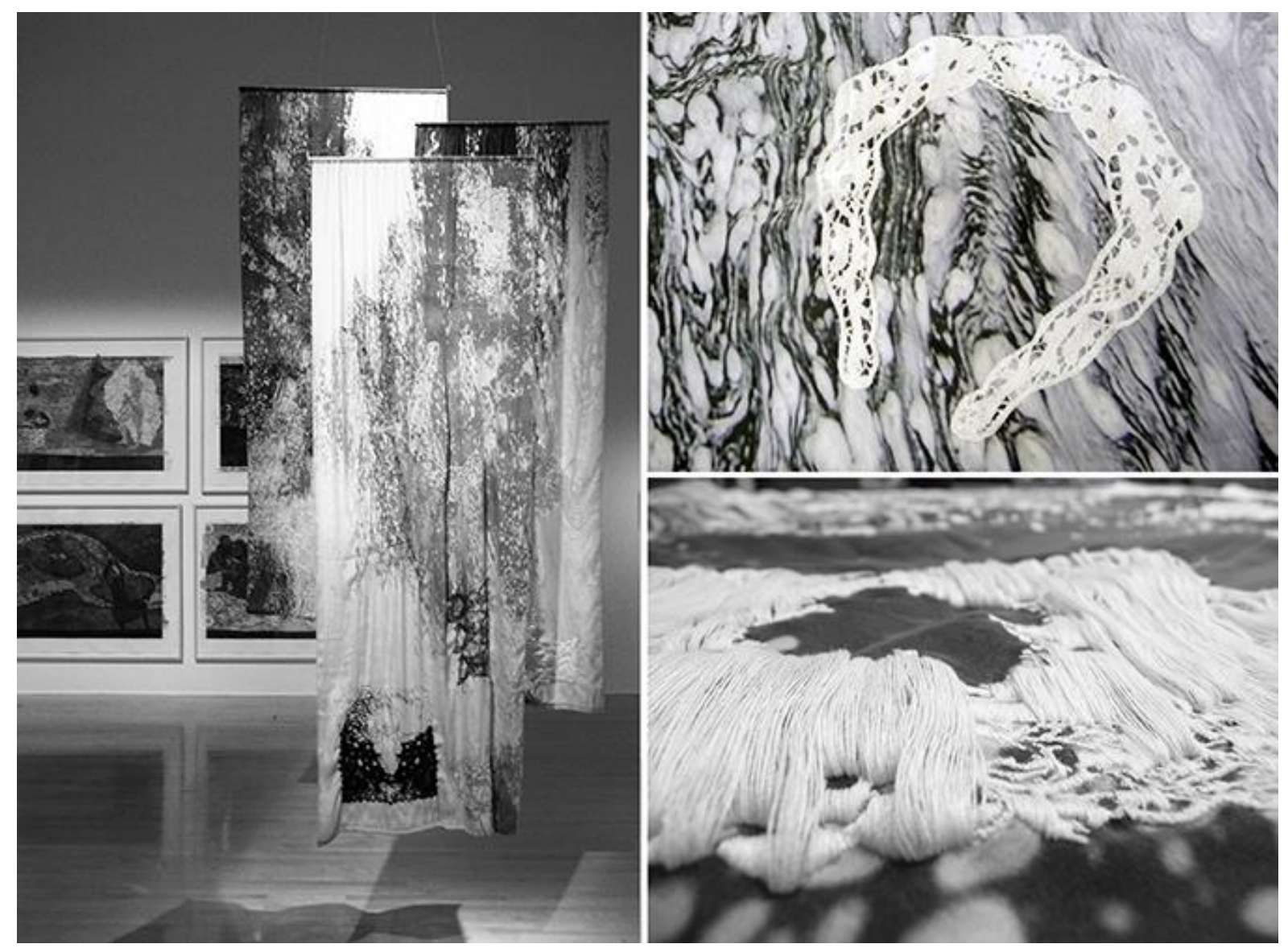

Figure 8a, b \& c: Katherine Townsend Lace Flow 1-3 in Closely Held Secrets exhibition, Bonington Galler; 8b: Horseshoe collar motif on digitally printed silk surface; 8c: Detail of a lace inspired motif showing the use of short and elongated stiches within the same design. Photographs by Whitmore () K.Townsend.

The resulting lengths constituted three experimental textile 'sketches'. On Lace Flow 1 and 2 the grey-scale silk (digitally printed with abstract patterns of fast slowing rivers) were embroidered with interpretations of lace collar and handkerchief designs from the Nottingham Trent Lace Archive. The motifs were stretched and distorted to replicate the idea of a lace fragments being dropped into a fast flowing current, translated through a combination of satin, short stabbed and long draped stitches in white matt cotton threads to create a contrast with the sheen of the base cloth (Figure 8b). On Lace Flow 3, red, black and white, running, tacking-style and floating stiches overlaid the print, leaving the viewer to decide which surface to look at first. This reflected the aim: to integrate the stitches so the threads followed and responded to the visual clues of the surface, adding a variable patina as opposed to a layer of embellishment. ${ }^{45}$ 


\section{Conclusion}

Closely Held Secrets challenged the process and perceptions of digital embroidery as a creative media by highlighting its potential application within a visual arts context. The embroidered artworks formed a diverse collection of images, canvases, fabric lengths and soft sculptures, were in a sense all 'super-objects' 46 in their own right-the process of collaborative exchange being as significant as the final crafted outcome.

The collaborations between Tony Taylor, Tessa Acti and the artists provided valuable insights into the aesthetic responsibility of the technician during the digitization and stitching out stages of digital embroidery production. Decisions were made and applied by them in varying degrees, according to the tacit knowledge and aspirations of the practitioners they were working with. While each of the creative partnerships worked differently, everyone involved had to accept artistic and technical compromises in order to complete the artworks for the exhibition deadline-in a similar way to how textile designers work in the commercial industry. The cooperative process of artistic translation, not only extended the artists' skill base, but revealed and elevated the role of the technician and the technology beyond that of 'faithful copier'. ${ }^{47}$ The cross-disciplinary research and making process demonstrated the flexibility of using both hand and computerized digitizing methods, to translate contrasting visual constructs, from the intricate patterns of handmade lace to untamed stich structures that float across the surface.

The artists using digital embroidery to 'replicate' and envision carefully conceived compositions, created artworks that were sophisticated, decorative and in some cases, quite traditional in terms of the application of the technology. However, all were challenging in their use of subject matter and/or their determination to interpret narratives inspired by elaborate hand stitched effects, using craft as an aesthetic and political position. ${ }^{48}$

Conversely, some of the more experimental approaches adopted by the 'exploratory' group were more focused on the unknown, serendipitous potential of the multi-head machine: how it could be played with or subverted to create unexpected material effects. Most artworks encompassed both replication and exploration of the medium simultaneously, with each artefact the result of a unique research journey. Whether traditional or experimental in terms of stitch application, of 
greatest significance was how the 'research through making' journey acknowledged the reciprocal relationship between artist and technician. The project also highlighted the importance of supporting opportunities for non-specialists to access and 'play' with digital textile technologies as alternative media to extend creative practice,

Closely Held Secrets celebrated the historical and conceptual significance of craft textiles. The project proved timely in a number of ways, preceding the Power of Making (2011) exhibition ${ }^{49}$ which celebrated the skill of the craftsperson and The Art of Not Making (2012) publication, ${ }^{50}$ which documented the emergence of a new kind of relationship between artist and artisan. Ultimately, the strength of the outcomes was not about the physical artefacts themselves, but how making artworks by 'other means' requires a sophisticated level of communication and reliance on the embodied knowledge and skills of all parties.

\section{Notes}

1. Tony Taylor, quoted in Grayson Perry, Artist's statement in Closely Held Secrets [exhibition catalogue] (Nottingham: Nottingham Trent University Bonington Gallery, 2010), 3.

2. Jean Baudrillard, The Vital Illusion (New York: Colombia University Press, 2000), 177.

3. Jane Harris, 'Digital Practice in Material Hands: How Craft and Computing Practices are Advancing Digital Aesthetic and Conceptual Methods', Craft Research 3, no. 1 (2012): 91.

4. Andrew Ure, A Dictionary of Arts, Manufacture and Mines (London: Longman, Orme, Brown, Green \& Longmans, 1839), 429.

5. Tony Taylor, Private Interview with Katherine Townsend, Nottingham Trent University, 20 July 2011.

6. David Thomas, 'Programming and Reprogramming Artworks: A Case of Painting and Practicing Conceptual and Media Art by Other Means', Intermédialités Journal 13. (Spring 2009): 89-113. <http://id.erudit.org/iderudit/044042ar>_[accessed 19 December 2014].

7 Coleman Schneider, Schiffli and Multi Head, New Jersey: Coleman Schneider, 1978, 1.

8. Christopher Frayling, 'Research in Art and Design', Royal College of Art Research Papers 1, no. 1 (1993): 5. 
9. Ibid.

10. Jean McNiff, Action Research, Principles and Practice, London: Routledge, 1999.

11. Donald Schön, Educating the Reflective Practitioner: Towards a New Design for Teaching and Learning in the Professions (San Francisco: Jossey-Bass, 1987).

12. Julian Malins and Carole Gray, 'Appropriate Research Methodologies for Artists, Designers \& Crafts Persons: Research as a Learning Process', in Proceedings of Making It, UK Crafts Council Conference (Wakefield: Woolley Hall, 1995), 3. <http://carolegray.net/Papers\%20PDFs/cc.pdf> [accessed 7 January 2014].

13. Taylor, Private Interview, 2011.

14. Taylor refers to Perry's 'subversion' as being related to his 'imprecise' use of controversial subject matter. This is a very different, but no less powerful connotation to the feminist context addressed by Rosika Parker in The Subversive Stitch (London: I.B.Tauris, 2010) (originally printed in 1984 by The Women's Press). 15. Grayson Perry in Jacky Klein, Grayson Perry (London: Thames \& Hudson, 2009), 113.

16. Taylor, Private Interview, 2011.

17. Ibid.

18. Charlotte Hodes, Artist's statement in Closely Held Secrets, 7.

19. Taylor, Private Interview, 2011.

20. Craig Fisher, Artist's statement in Closely Held Secrets, p.6.

21. Ibid.

22. Tessa Acti, Private Interview with Katherine Townsend, Nottingham Trent University, 21 March 2011.

23. Neoprene, styrofoam, felt, cotton, Dupont silk \& car upholstery were used to create soft sculptures of industrial salvage for the 'embroidered shits' to be placed on, as if left in the corner of a builders yard.

24. Craig Fisher, Hazardous Materials [exhibition catalogue] (Plymouth: Plymouth College of Art, 2008).

25. Faith Kane, 'Digital Embroidery and Expression: A Review of Closely Held Secrets', Craft Research 1, no. 2 (2011): 161-8.

26. Danica Maier, Private email correspondence with Katherine Townsend, $11^{\text {th }}$ September, 2011.

27. Ibid. 
28. Acti, Private Interview, 2011.

29. Derek Sprawson, Private email correspondence with Katherine Townsend, $17^{\text {th }}$ October, 2011.

30. Taylor Private Interview, 2011.

31. Sol LeWitt quoted in Thomas, Programming and Reprogramming Artworks, 32.

32. Stella Whalley, Tokyo Tales (England: Design United Worldwide, 2007).

33. Stella Whalley, Private email correspondence with Katherine Townsend 14 September 2011.

34. Harris, 'Digital practice in Material hands', 2012.

35. Thomas, 'Programming and Reprogramming Artworks, 2009, 24.

36. Taylor, Private Interview, 2011.

37. Taylor worked with Lace Market Embroidery, Nottingham but their commercial production precludes the time or flexibility for them to be able to reposition the fabric around to assimilate the stitch with the digitally printed images on the fabric.

38. Acti, Private Interview, 2011.

39. Geoff Diego Litherland, Private interview with Katherine Townsend, Nottingham Trent University, 21 March 2011.

40. Ibid.

41. The over-stitching process stresses the machine, as it is designed to operate on a smooth taught surface, but as the design demonstrated a multi-layered effect can be achieved if this is not adhered to strictly.

42. Litherland, Private interview, 2011

43. See also, Katherine Townsend and Joy Buttress, 'High Falls: Water, Lace and the Body', DUCK Textile Journal 1 (2010).

44. Katherine Townsend, Artist's statement in Closely Held Secrets, 12

45. Marguerite Dessanay, 'Following the Thread: Art \& Craft; An Embroidered Web', Elephant: The Arts \& Visual Culture Magazine 9 (Winter 2011): 74-95.

46. Louise Manzanti, 'Super-Objects: Craft as an Aesthetic Position', in Maria Elena Buzek (ed.), Extra/Ordinary: Craft and Contemporary Art (Durham: Duke University Press, 2011), 60-81.

47. Tony Taylor, Artist's statement in Closely Held Secrets, 3.

48. Louise Mazanti, 'Super-Objects: Craft as an Aesthetic Position', in Maria Elena Buzek (ed.) Extra/Ordinary Craft: Craft and Contemporary Art (Durham: Duke University Press, 2011). 
49. See: Daniel Charny, The Power of Making: The Importance of Being Skilled (London: V\&A and the Crafts Council, 2011).

50. The relationship between the artist and technical expert is also discussed in Michael Petry, The Art of Not Making: The New Artist/Artisan Relationship (London: Thames \& Hudson, 2012).

\section{Bibliography}

Baudrillard, Jean. The Vital Illusion. New York: Colombia University Press, 2000.

Charny, Daniel. The Power of Making: The Importance of Being Skilled. London: V\& A and the Crafts Council, 2011.

Dessanay, Marguerite. 'Following the Thread: Art \& Craft, An Embroidered Web', Elephant: The Arts \& Visual Culture Magazine 9 (2011): 74-95.

Fisher, Craig. Hazardous Materials [Exhibition Catalogue]. Plymouth: Plymouth College of Art, 2008.

Frayling, Christopher. Research in Art and Design: Royal College of Art Research Paper 1, no. 1 (1993).

Harris, Jane. 'Digital practice in Material hands: How Craft and Computing Practices are Advancing Digital Aesthetic and Conceptual Methods', Craft Research 3, no. 1 (2012): 91-112.

Kane, Faith. 'Digital Embroidery and Expression: A Review of Closely Held Secrets', Craft Research 1, no. 2 (2011): 161-8.

Klein, Jacky. Grayson Perry. London: Thames \& Hudson, 2010.

Litherland, Geoffrey Diego, Tony Taylor, Katherine Townsend, Tessa Acti and Helen Garrigan. Closely Held Secrets [Catalogue of an exhibition held at Bonington Gallery, 29 October - 24 November 2010]. Nottingham: Nottingham Trent University, 2010.

Malins, Julian, and Carole Gray. 'Appropriate Research Methodologies for Artists, Designers \& Crafts Persons: Research as a Learning Process'. In Proceedings of 'Making It'. UK Crafts Council conference, Wakefield: Woolley Hall, 1995. <http://carolegray.net/Papers\%20PDFs/cc.pdf> [accessed 7 January 2014]. Mazanti, Louise. 'Super-Objects: Craft as an Aesthetic Position'. In Extra/Ordinary Craft: Craft and Contemporary Art, edited by Maria Elena Buzek, pp.59-83, Durham: Duke University Press, 2011. 
McNiff, Jean. Action Research, Principles and Practice. London: Routledge, 1999.

Parker, Rosoka. The Subversive Stitch. London: I.B.Tauris, 2010 (originally printed in 1984 by The Women's Press).

Petry, Michael. The Art of Not Making: The New Artist/Artisan Relationship. London: Thames \& Hudson, 2012.

Schneider, Coleman. Schiffli and Multi Head. New Jersey, USA: Coleman Schneider, 1978.

Schön, Donald. Educating the Reflective Practitioner: Towards a New Design for Teaching and Learning in the Professions. San Francisco: Jossey-Bass, 1987.

Thomas, David. 'Programming and Reprogramming Artworks: A Case of Painting and Practicing Conceptual and Media Art by Other Means. Intermédialités Journal 13 (Spring 2009): 89-113. <http://id.erudit.org/iderudit/044042ar> [accessed 19 December 2014].

Townsend, Katherine and Joy Buttress. 'High Falls: Water, Lace and the Body'. DUCK Textile Journal (2010)

<http://www.lboro.ac.uk/microsites/sota/duck/volume1.htm>[accessed 19 December 2014].

Ure, Andrew. A Dictionary of Arts, Manufacture and Mines. London: Longman, Orme, Brown, Green \& Longmans, 1839.

Whalley, Stella. Tokyo Tales. England: Design United Worldwide, 2007. 